\title{
PULSATING MAJOR SPORT EVENT ORGANIZATIONS: A FRAMEWORK FOR INDUCTING MANAGERIAL PERSONNEL
}

\author{
CLARE HANLON* and GRAHAM CUSKELLY $\dagger$ \\ *Victoria University, Australia \\ $\dagger$ Griffith University, Australia
}

\begin{abstract}
In 1990 Toffler coined the term "pulsating organization" to reflect organizations that expand and contract. This term has relevance for major sport event organizations. They generally operate with a small core of personnel for much of the year, expand substantially in the lead up to an event, then afterwards personnel numbers shrink in size. This effect poses substantial challenges in delivering a quality induction process for many major sport event organizations. The first part of this study identifies how these "pulsating organizations," in light of their special characteristics, have adapted an induction process from "generic" organizations. The second part incorporates semistructured interviews with managers at the Australian Open Tennis Championships and the Australian Formula One Grand Prix to ascertain their induction process before a major sport event. The final part recommends a model to improve the management of induction at these two organizations. On a broader scale, managers of other pulsating major sport event organizations could incorporate this model, when developing, implementing, and evaluating their induction process.
\end{abstract}

Sport event organizations Managerial induction Pulsating organizations Induction process

Major sport events play a significant role in generating tourism and economic activity on a national and international scale (Green, 2001; Jago \& Shaw, 1998). They have positive economic benefits (Spilling, 1996), increase public awareness (Torkildsen, 1992), and create pride and a positive community image (Getz, 1997; Hall, 1992). With this in mind, it is important to effectively manage personnel, who comprise full-time, outsource, and seasonal personnel (Graham, Goldblatt, \& Delph, 1995), in order to ensure the success of the event. One integral human resource management
(HRM) component to ensure effective personnel management is induction (Doherty, 1998). In this article, induction refers to a program covering facets of the major sport event organization, and information to assist managers with their roles and responsibilities.

Toffler (1990) referred to organizations that expand and contract over their commercial life cycle as pulsating organizations. Crawford's (1991) research expanded this definition, referring to them as holding organizations with temporary work units that evolve and dissolve according to environmental change, consisting 
of personnel in small, cross-disciplinary teams. Major sport event organizations share the characteristics of such pulsating organizations, whereby the number of managers employed in the lead up to an event increases substantially, peaking, and then falling afterwards (Hanlon \& Jago, 2000). Pulsating organizations are quite different to "generic" organizations. The latter organizations have a relatively stable workforce and hence, established relationships between personnel, and the induction of new personnel is commonly performed on an individual basis. In contrast, induction is more likely to be performed on a group basis at pulsating major sport event organizations, due to the influx of personnel over a limited period of time.

Minimal research has been conducted regarding pulsating organizations. Researchers such as Toffler (1990) and Crawford (1991) provide a brief overview of the characteristics and operations of such organizations, but little is known about the process of inducting large numbers of personnel to an organization within a limited period of time. Therefore, the aim of this article is to describe the induction processes incorporated by managers at two pulsating major sport event organizations in the delivery of two separate major sport events. These two organizations directly manage full-time, outsource and seasonal managers, and consequently, these shall be the management categories referred to in this study. Full-time is used in the context of personnel who are employed for an unlimited period of time (Brown, 1996). Outsourcing is when an organization moves its internal work to an external supplier (Elliott \& Torkko, 1996). Seasonal is used in the context of personnel who are employed for an event for a limited period of time, whether it be for a day during the event or up to 6 months (Graham et al., 1995).

Specifically, the article first describes how pulsating major sport event organizations have adapted the induction process from "generic" organizations. Second, it discusses the results of the semistructured interviews conducted with a number of managers at the two major sport event organizations. Finally, it provides a recommended induction process suitable for these two organizations and possibly other pulsating major sport event organizations.

\section{The Case for Induction}

Managers often believe that the induction process can be time consuming and expensive (Mull, Bayless,
Ross, \& Jamieson, 1997; Slack, 1997). Despite this negative view, managers conduct such a process for their personnel. A well-designed induction process that is implemented in a timely manner has been shown to reduce the level of personnel anxiety (Schermerhorn, Naumes, \& Naumes, 1993), increase personnel retention (Cooke, 1997; Seaver, 1997), and improve the level of personnel productivity (Seaver, 1997) and dependability (Cuskelly, 2000).

Despite the importance and benefits of an induction process leading to organizational effectiveness (Doherty, 1998), research has neglected to address this in relation to pulsating major sport event organizations. However, recognizing such neglect is not new, as almost a decade ago Larsen, Montelpare, and DonovanNeale (1992) reported that sport organizations failed to provide satisfactory induction opportunities for their personnel.

\section{Implications of the "Generic" Organization Induction Process for Pulsating Major Sport Event Organizations}

From the literature reviewed, four common steps are evident within the "generic" organization induction process. These are: providing an organizational framework, where the organization's vision, goals, and general expectations are discussed (Blyton \& Turnbull, 1992; Legge, 1995; Pessin, 1997; Seaver, 1997); establishing relationships that incorporate team training (Blyton \& Turnbull, 1992; Henkoff, 1993) and create a stronger, more resilient organization (Wheatley, 1997); providing resources such as a manual (Critten, 1994; Flynn, 1996; Pessin, 1997; Seaver, 1997); and evaluating the induction process (Seaver, 1997). These steps complement those of Katz and Kahn's (1978) research regarding the types of information required for personnel, namely: specific task directives; the job rationale; the company, and its policies; feedback about work performance; and information on the organization's goals.

With an induction process being emphasized for organizations within literature, it is important to incorporate this into pulsating major sport event organizations. However, with scant literature addressing an induction process within these organizations, the four-step induction process from "generic" organizations has been adapted. In addition, the characteristics of pulsating major sport event organizations have been taken into 
account in order for the process to be suitably implemented.

These characteristics comprise full-time, outsource, and seasonal managers who all have different needs, attitudes, and expertise, forming temporary work units consisting of small cross-disciplinary teams (Hanlon, 2001). The majority of managers (outsource and seasonal) have limited time within the organization, thus creating an expansion and contraction of personnel and causing the organization to pulsate (Hanlon \& Jago, 2000). Prior to the event, these personnel require information about the organization and their designated role (Go, Monachello, \& Baum, 1996; Nankervis, Compton, $\&$ McCarthy, 1996). Because of these characteristics, induction needs to be quick, timely, and effective, in order for personnel to be at their optimum level of performance in time for the event.

Sport management literature has adapted the "generic" organization induction process and applied it to sport organizations (Slack, 1997; Smith \& Stewart, 1999). For example, introducing personnel to the organization's framework is an important step in the induction process for sport organizations (Slack, 1997; Smith \& Stewart, 1999). Such an introduction involves providing new personnel with information regarding the sport organization's vision, goals, and general expectations (Smith \& Stewart, 1999).

When incorporating the second step of establishing relationships, Peters (1993) suggested personnel courses that involved "making relationships with outsiders" (p. 305) should be held for full-time employees. This would ensure a smooth transition process where full-time personnel would identify ways that outsource and seasonal personnel could complement their role without regarding them as a threat. The Victorian Racing Club, which organizes the Melbourne Cup, among other major events, had another strategy to establish relationships during induction. This club conducted a management course, involving induction sessions such as racing industry induction, handling the media, negotiation, time management, personal productivity, and customer service (Victoria Racing Club, 1997).

With resources being the third step of the induction process, sport management literature reveals a manual as an effective tool. For example, the Victorian Racing Club provides a handbook to employees. The Employee Induction Handbook identifies the employee's rights and obligations for working at any club within Victoria (Victoria Racing Club, 1997). Because a variety of per- sonnel arrive and depart at various periods within a limited time near the cup, this handbook is considered an effective induction resource (Victoria Racing Club, 1997).

Finally, evaluating the induction process has been emphasized as a pivotal step for sport organizations (Culkin \& Kirsch, 1986). Culkin and Kirsch recommended incorporating methods such as informal and formal interviews, questionnaires, and observation. Furthermore, Dale and Iles (1996) recognized report writing in order to evaluate the success of induction.

However, evaluating the success of induction is difficult at pulsating major sport event organizations, because time is limited due to the majority of personnel (outsource and seasonal) who are usually appointed for the event days. In light of this problem, Dale and Iles (1996) recommended using detailed documents outlining employer expectations in order to measure success. This further confirms the appropriateness of resource manuals, whereby common questions are immediately answered. A prime strategy to evaluate the manual's success was suggested by Pessin (1997); that is, to conduct related event experiences prior to the main event, trialing the manual during this time. For example, in preparation for the 1989 Australian 500CC Motorcycle Grand Prix, personnel were used in club, national, and international events at the circuit in the lead up to the major event (Barnard, 1990). Not only would this evaluate the success of a manual, conducting an event before the major event would also assist with establishing relationships between the variety of personnel. Research has found such test events are essential for major sport events (Brown, Sutton, \& Duff, 1993).

On the other hand, Mull et al. (1997) found that regardless of how much induction occurs, personnel will not be fully prepared for handling every circumstance, knowing all the answers, or consistently performing new skills. In order to alleviate this situation, Pessin (1997) recommended the provision of a comprehensive formal induction process that is constantly reviewed.

However, gaps within this literature reveal that research has neglected to determine a comprehensive formal induction process for pulsating major sport event organizations. Furthermore, when these organizations are discussed, their specific characteristics have not been applied to the four-step induction process; for example, how and when these steps can be implemented to fulltime, outsource and seasonal managers, many of whom are employed for a limited period of time. Consequently, 
research is required to determine what a comprehensive formal induction process comprises for pulsating major sport event organizations.

\section{Method}

In order to ascertain how induction was performed within pulsating major sport event organizations, two annual events were selected. The two events chosen were the Australian Open Tennis Championships (AOTC) and the Australian Formula One Grand Prix (AFOGP).

These two events were chosen because they are internationally sanctioned by their relevant international sport federations and because they have several important differences in their characteristics, including:

- History of the event (AOTC began in 1968 while the AFOGP began in 1996);

- Duration of the event (AOTC for 2 weeks and the AFOGP for 4 days);

- Management (AOTC relies largely on internal management sources, whereby personnel are employed directly by the organization; the AFOGP relies largely on outsource management, whereby personnel are employed directly by outsource organizations);

- Organizational size (over a period of 8 months, the AOTC expands from 20 to 4000 managed outsource and seasonal personnel, whereas the AFOGP employed seasonal personnel resulting in numbers increasing from 40 to 45 managed personnel; however, due to the vast array of outsourcers, exact numbers for directly managing these personnel were not known. According to one full-time informant, there are "approximately 15,000 personnel associated with outsourcers").

Semistructured interviews were considered the most effective method due to the depth of information that could be gathered (Minichiello, Aroni, Timewell, \& Alexander, 1995). Through the literature, issues emerged that acted as a guide to the development of the core interview questions.

Three levels of managers were identified for interview within each organizational structure: Chief Executive Officers (CEO), department managers, and coordinators. The full-time department managers were directly responsible to the CEO. In this case, a homo- geneous group of department managers who managed full-time, outsource and seasonal coordinators were selected using stratified sampling (Minichiello et al., 1995). The coordinators were directly responsible to department managers. In this case, coordinators were purposefully placed into homogenous categories, who managed full-time, outsource and seasonal personnel, and were selected using purposeful random sampling (Babbie, 1998).

A total of 21 interviews were performed: 2 CEOs, 8 department managers, and 12 coordinators. This amounted to 10 interviews with the AOTC and 11 interviews with the AFOGP. Interviews were first conducted at the AOTC and once information was saturated, interviews were then performed at the AFOGP. To ensure there was no bias towards what should be occurring for managers (e.g., from top-down management level), interviews were based on availability. The semistructured interviews, each lasting about 1.5 hours, were conducted in standard meeting rooms at the respective manager's organization. Each interview was taped, transcribed, and analyzed before the next interview was conducted.

Once interviews were performed and transcripts approved by the interviewees, the output was then entered into NUD*IST qualitative data analysis software. Data were coded and indexed for both theme and content. A second researcher also coded the data using a manual dual coding process. Babbie's (1998) approach was used wherein the lead researcher explained the code category meanings and then distributed the first transcript. Coding comparisons were then made with discrepancies being discussed and coding modified in light of the discussion. The check-coding procedure was performed four times, twice for each site, to ensure that coding schemes were similar. Table 1 illustrates the nodes identified, whereby three parts of an index treemanuals, tailored programs, and combined sessionscontained specific nodes. Manuals and tailored pro-

Table 1

Induction Nodes Identified at the AOTC and the AFOGP

\begin{tabular}{lcc}
\hline Manuals & Tailored Programs & AFOGP Combined Sessions \\
\hline $\begin{array}{l}\text { On-site } \\
\text { Office }\end{array}$ & Full-time managers & General event \\
& Outsource managers & Management brief \\
& Seasonal managers & Risk-based \\
& On-site
\end{tabular}


grams were evident within both organizations; however, combined sessions were conducted only at the AFOGP.

This study, which was part of a larger research project, involved a triangulated process whereby secondary and primary data were collected. For the purpose of this article, secondary data were systematically compared (Denzin \& Lincoln, 1994), whereby policy documents and operation manuals used by managers for induction purposes were gathered. The accessible documents were examined in order to assess the subjective responses that evolved from the informants. However, this information was difficult to obtain due to the lack of available documentation in some instances. The primary data involved a series of semistructured interviews with managers from the AOTC and the AFOGP. These interviews were conducted in 1998 and 1999, respectively. Interviews were performed in order to obtain information on how fulltime, outsource and seasonal managers were inducted. This article refers to these interviewed managers as informants, thus excluding their role and level, and ensuring the manager's anonymity is protected.

\section{Results}

Results indicated that AFOGP full-time and outsource managers experienced the first three of the four-step induction process identified from literature: being provided with an organizational framework, establishing relationships, and being provided with resources (manuals). Furthermore, results highlighted how the four steps became more specific when applied to the two sampled pulsating major sport event organizations. For example, outsource managers established relationships during combined induction sessions with other categories of managers. There was inconsistent information relating to the intensity of induction at the AOTC, and this also applied to seasonal managers at the AFOGP.

Documenting the induction process at the AOTC and the AFOGP was in the initial draft stage. Consequently, there was a lack of operational documentation available. However, two common issues emerged from the data analysis process: induction manuals and induction tailored for each management category. Unbeknown to informants, these issues have resulted from the characteristics of pulsating major sport event organizations - that is, the fluctuation of varied personnel, all with different needs, attitudes, and expertise who form temporary, small cross-disciplinary teams for a limited period of time (Hanlon, 2001). Despite the similarities, there were also a number of differences between the AOTC and the AFOGP. One notable example was the variety of combined management induction sessions conducted at the AFOGP, whereas no such sessions existed at the AOTC. The similarities and differences are revealed in the following section.

\section{Induction Manuals}

One resource provided by both organizations was on-site induction manuals. In each case, there was an overview of the event, maps, policies, contact details, and a minute-by-minute outline of the events program. Due to a variety of managers employed at the respective events for a limited period of time, these manuals were vital resources to provide work guidelines and ensure questions were quickly answered. In addition, an office manual was being drafted at the AFOGP for full-time and seasonal managers.

On-Site Manual. Both organizations produced a general on-site manual for all their managers. The AFOGP on-site manual contained more detail regarding safety issues, corporate details, and specific operations conducted by particular department teams. One AFOGP informant commented on the importance of this manual, stating "that handbook is probably the most valuable asset that they have." In support of this comment, every AFOGP outsource informant commented that the induction process for their managers was assisted through the AFOGP's induction manual, as it ensured continuity existed between the organizations involved with the event.

The AFOGP also produced specific on-site manuals for different departments, outsource companies, or roles. These manuals generally included event and safety information, and then specific information relating to the employee's role. For example, the Security manual informed security managers about general event information and specific details relating to their role and security procedures. Each manual required managers to sign the manual stipulating it had been read and that their role was clearly understood.

Office Manual. The AFOGP office manual was in its initial stages of implementation and comprised information such as equal opportunity, office layout, poli- 
cies, procedures, and history about the organization. The manual was provided for full-time and office-based seasonal managers. A seasonal informant recommended, with computer access, the office manual be accessible on the computer network for quick referral and updated event information.

\section{Induction Programs Tailored for \\ Each Management Category}

Informants emphasized the importance of ensuring appointees were immediately involved within the organization. One informant commented that "induction is about getting them on board, getting the work in front of them, but also trying to blend them into the family." A word frequently referred to by informants was "formalization." This was used in the context of the need for a documented induction process that was consistently practiced by event managers to all management categories. However, there was evidence of different induction processes for each management category. Full-time managers at the AOTC and the AFOGP were individually inducted. Outsource managers at the AFOGP were inducted as a group, whereas at the AOTC no induction sessions occurred for outsource managers. Seasonal managers at the AOTC and the AFOGP were inducted in a general way, but it was often inconsistent and haphazard. For example, at the AFOGP induction was performed for an hour once a month. Consequently, one full-time informant admitted, "sometimes it means that someone may be here for 3 weeks before they have an induction, but at least they have something."

Inducting Full-Time Managers. Within both organizations, the general practice for inducting full-time managers was similar. The induction process commenced prior to their arrival, and continued on the first workday. Reviewing the induction was also similar at the AOTC and AFOGP. Once a person was selected, the human resource manager (HRM), or the manager to whom the person was directly responsible, contacted the person to congratulate him or her. An organization information booklet was mailed to the appointee to be read prior to starting the new position. Also included in the package were forms and paperwork to be completed and returned before the appointee's first day. These forms gathered personal information and facilitated the appointee's access to the building, computer system, and other resources.
On the first work day, the appointee was introduced to the department team. When time permitted, the appointee went through a transition that involved observing the current employee in the role and being informed of organizational expectations. This transition was recognized as a nurturing process. An e-mail was also sent to all managers within the organization informing them of the new member and his or her role.

Informants agreed that it was important for the appointee's manager to perform a job preview with the appointee to ensure questions were answered and satisfaction was evident. These informant views represented how the induction process could be improved to ensure a more consistent and formalized procedure existed. In particular, every AOTC informant noted the need for a more formalized induction process for new appointees.

At the AOTC, there were contradictory reports regarding the intensity of induction. Two informants, who were directly responsible for new managers, commented that the appointee was provided with the staff handbook and the content was discussed. This handbook contained general information such as emergency procedures and occupational health issues and safety. According to one of these informants:

I would spend a number of days with the person, going through things and leaving them alone to read through everything. I'd take them around or have one of my staff do it, depending on the position of course.... You try and get them set up as quickly as possible.

On the other hand, one AOTC informant summarized induction by saying that appointees "are given a general introduction by being shown around the place, yet not everyone is there. Little information is also provided about the vision, mission statement, policies, and personnel rights." The two informants admitted that providing such an intense induction was in its initial stage, with few managers being aware of its existence. This may explain the informant contradiction regarding the intensity of the induction process.

Unlike the AOTC, who spent a number of days informally inducting the appointee, the AFOGP induction process consisted of an intense, formal, 3-hour session. During the session, the HRM provided information about the event and the organization, as well as organizational processes and policies. This information was reinforced through an induction manual for future reference. The relevant department manager and asso- 
ciated coordinator provided specific information relating to the department and to the appointee's role. Other department managers provided information concerning their departmental responsibilities. Outsource managers who were specifically dealing with the appointee also presented information relating to their role.

Inducting Outsource Managers. In the case of outsource managers, induction was performed at the management level with both organizations directly liaising with these managers. Contracts were confirmed at least 6 months before the respective event, thus allowing sufficient time to induct outsource managers. The majority of these managers were employed on long-term contracts. However, regardless of their employment time, all outsource informants emphasized the need for their event organization to induct new and continuing outsource managers. They believed this was of vital importance, with one (continuing) informant saying:

Outsource managers have to be inducted in the spirit of the event. Anybody who doesn't believe and understand the history, integrity, and the heritage of the event will not be proud to work in it, and building the pride is part of the first stage.

Induction at the AOTC consisted of being provided with last year's posttournament report and operation manuals. According to a minority of full-time informants, the outsource contracts contained specific clauses so that expectations were clear. They expressed the view that, with their managers returning each year, there was no need for a formal induction process. If procedures changed, relevant information would be sent to these managers. The induction of new and continuing outsource managers usually coincided with a busy time. According to one AOTC full-time informant, outsource managers were warned, “we (AOTC) won't have that much time, it'll be full on, there's a huge learning curve and you've got to be up to speed pretty quickly." Outsource informants were generally disappointed with this lack of induction. According to one outsource informant:

There's some of us who've been there for 20 years and some people who've worked there the last 10 and I have no idea who they are. We come in, we do our job ... and we go out.

In contrast, at the AFOGP, a formal induction session was specifically conducted for outsource manag- ers. A "culture session" introduced topics such as the philosophy, culture of customer service, venue layout, possible problems, patrons, and the roles of various employees. As one full-time informant admitted, "It's a lot of information in a short period of time, but there are a variety of speakers."

With such an emphasis on induction by the AFOGP, outsource informants stressed the need for this organization to place more weight on the induction time required within the tender brief. In doing so, outsourcers would be more prepared for the high expectations and amount of induction time required with the AFOGP.

Inducting Seasonal Managers. In theory, within both organizations induction was considered important for seasonal managers. This is evidenced in a paragraph within the AOTC Casual Employment Application Form:

In pursuit of excellence it is crucial that all successful applicants attend all briefing and training sessions that are notified. ... These sessions assist in developing team dynamics, communication and continuous improvement of the Australian Open and your commitment to the above period includes these sessions. (1998 Australian Open, January 18-31, Casual Employment Application, pp. 34)

This expectation was not delivered in practice. No seasonal informants made reference to the existence of such a policy. In fact, informants from both organizations made reference to the lack of induction for seasonal managers.

Within both organizations, the amount of induction provided for seasonal managers was dependent upon when they were appointed in relation to the event (e.g., 1 month leading up to the event). For example, a very informal briefing was delivered to seasonal managers due to time limitations and the term of their appointment. One informant acknowledged that generally seasonal managers "could sink or swim if office-based and become unguided missiles." Another informant commented, "a great deal of success within an organization is not only knowing your job but knowing how the organization works. That's where it's difficult with the casuals, they don't have that opportunity to gather that knowledge." This explains why the themes of lack of induction and recommendations emerged from the informant's response.

Full-time informants at the AOTC and the AFOGP acknowledged office-based induction was conducted for 
their seasonal office managers. However, evidence from seasonal informants questions its existence. The process at the AOTC illustrates this point. According to several full-time informants, office-based induction for newly appointed seasonal managers consisted of spending 10 minutes before the working group meeting with their supervisor and with relevant members of the team. However, this was not recognized by seasonal informants, one of whom commented, "we are meant to be inducted each year, however, it has not been performed." When prompted on this point, informants mentioned tournament information had been sent to them; however, they did not recognize this as formal induction. From the seasonal informant responses, there was a perception of being left out of formal induction activities.

Similar to the AOTC, at the AFOGP there was contradictory evidence regarding office-based induction. Seasonal office-based informants responded that no formal induction process was conducted after their appointment, whereas two full-time informants explained the monthly 1-hour induction process for seasonal managers. The content consisted of the HRM providing an overview of the organization and explaining the legal side of who they were and what they did, which was mainly event driven. The inductors also discussed the coming event rather than the processes involved in managing the event.

Despite the ambiguity of office-based induction at the AFOGP, specifically designed on-site induction sessions for seasonal managers were evident. The term onsite induction was used in the context of managers conducting duties that were based at the event venue. These sessions were performed as close to the event as feasible, as justified by one informant, "any longer they would probably forget some of the finer points that we tried to reinforce." For example, night seasonal managers had a detailed briefing 1 week before the event with extensive notes for future reference. The observer induction program, for seasonal managers appointed to observe specific areas of the event, was held 5 days before the event. Generally these sessions included: addressing the event in terms of layout, problems that may be experienced, the patrons, and types of people working at the event.

Seasonal informants from both organizations made reference as to how induction could be improved for seasonal managers. At the AOTC, seasonal managers required information on the extent of how their organization inducted seasonal personnel. These managers could then complement the induction process, for example, by providing specific information about their role and introducing team members.

The AFOGP seasonal informants recommended the need for a formal office-based induction process. This would involve embracing the event's vision, learning about the organization and the departments relating to the position, asking questions about the event manual, explaining the structures, providing an office tour, and introducing them to respective managers for immediate team inclusion. Furthermore, once a general overview of the organization and the event was provided, their respective manager would then discuss the requirements, job duties, expectations, and organize a weekly progress meeting. With no formal seasonal manager induction booklet, one informant developed his own to ensure the next person in the position would not experience the complications he had experienced. The booklet included information such as contacts, job description, and additional duties outside the description.

\section{Combined Induction Sessions at the AFOGP}

Informants from both organizations emphasized the importance of providing additional induction programs that involved inducting all categories of managers in combined sessions. However, at the AOTC there was no evidence of these sessions. Consequently, data provided in this section concentrate on the induction sessions performed with the combined management categories at the AFOGP. Four induction sessions were conducted: a general event induction, a management briefing, a risk-based induction, and on-site inductions. One informant justified the importance of these sessions, commenting "if you don't support your staff at the event and people are working long hours, a lot of things tend to happen. You can't expect them to perform at the peak of what they're doing."

General Event Induction. A general event induction was provided for full-time and seasonal managers. The session was compulsory, all managers were paid to attend, and the session was conducted as close to the event as feasible. Kits were provided and contained the event's program, updates, and what outsource managers were required to provide to specific areas.

Management Brief. The management brief was designed for all management categories, with its purpose to ensure everyone had the same objectives. Content 
within the brief involved role-playing, scenarios, and presentations specifically relating to the event. Informants commented favorably that the brief and associated team-building exercises assisted with the development of teams.

Risk-Based Induction. Risk management consultants presented a risk-based induction session to the AFOGP committee and all management categories. This involved a detailed session that reviewed risks and the risk management plan. The consultants provided information so that managers were able to know how to react in certain situations (e.g., crowd control and controlling access). Role-plays were performed, covering "what if" situations, such as someone refusing to open their bag. Managers then reciprocated this risk-based induction to their team members.

On-Site Induction. On-site induction was conducted for all on-site managers directly employed by the AFOGP. Most informants viewed the on-site sessions as vital but regimented. These comprised the on-site session, on-site safety session, and on-site tours.

During the 1-hour on-site session, topics such as industrial issues, work cover safety, interpersonnel relationships, and knowing how to react in an emergency situation were discussed. At the circuit, an on-site safety session entailed a 30-minute safety test. Once managers had performed these two sessions, they signed a form confirming their involvement. Understandably, informants emphasized that on-site managers had insurance provisions.

For the 2 months preceding the event, 2-hour on-site circuit tours were performed every Saturday, for onsite employees directly employed by the AFOGP. The sessions involved talking to people around the circuit so managers knew where everything was. However, this induction at a nonpermanent venue was difficult. As summarized by one full-time informant:

I take all the staff and show them "this is where this is." It's very difficult to say until the checkered flag goes up, but "this is where the checkered flag goes," "this is Fangio stand," etc. We try to explain because until you actually see it on face value you can't actually envisage what's there. You can look at a map and it looks alright there, but you can't work out sight lines, you can't work out undulations. It's probably the hardest part.

In summary, the common form of induction for all management categories, at both organizations, was pro- viding on-site manuals. Specifically, at the AOTC, there was inconsistency from full-time informants regarding the induction process they were involved in. Outsource managers were provided with reports from the last tournament, and there were inconsistent responses concerning the induction process for seasonal managers. At the AFOGP, full-time managers experienced an induction process comprising an overview of the organization and established relationships with associated managers. Outsource managers experienced a less intensive overview of the organization and established relationships through combined induction sessions with all categories of on-site managers. Contradictory evidence on the induction process for seasonal managers existed with uncertainty of office-based induction and a lack of resources. However, on-site induction was provided to seasonal managers, which involved providing an overview of the event and being involved in combined induction sessions with all on-site managers.

\section{Discussion}

The aim of this article was to describe the induction processes incorporated by managers at two pulsating major sport event organizations in the delivery of separate major sport events. Vital results, strategies, and gaps have been identified. The results reinforce sport management literature that specifically referred to the necessity of inducting new personnel (Slack, 1997; Smith \& Stewart, 1999). However, in this study, not only was an induction process important for new managers, but informants stressed the need to induct all management categories before an event, irrespective of whether they were new to the organization or had been employed for a number of years.

One effective strategy incorporated by both organizations was induction manuals. Clearly, induction manuals, in particular on-site manuals, were considered an important resource within the AOTC and the AFOGP. This is a vital induction process that distinguishes major event organizations from "generic" organizations. That is, due to the limited time and questions immediately requiring answers during an event, on-site manuals became a vital resource, particularly for seasonal managers who had experienced minimal induction. Such reliance on induction manuals reinforces literature that emphasized these as a valuable induction resource (Flynn, 1996; Pessin, 1997; Seaver, 1997). 
Another effective strategy incorporated by the AOTC and the AFOGP, and consistent with literature, was the content within the induction session for full-time managers. Despite the intensity of this session varying between the two organizations, the content remained similar. Full-time managers were oriented to the organization's framework where a common understanding of the organization and its culture was formed (Legge, 1995), and the organization's vision, goals, and general expectations (Pessin, 1997, Slack, 1997; Smith \& Stewart, 1999) were emphasized with topics including the organization's history, initiatives, structure, and internal relationships (Seaver, 1997).

One important difference between the two organizations was that the AFOGP placed more emphasis on an induction process for outsource managers than did the AOTC. One reason for this at the AFOGP could be the high level of reliance it had with outsource organizations and managers, compared with the handful of outsource managers appointed by the AOTC. Furthermore, the AFOGP event organizations faced greater risks, because it was a motor sport event at a nonpermanent venue. The AOTC event involved less risk, because it was a tennis tournament, conducted at a permanent purpose-built venue.

The AFOGP incorporated active formal induction sessions (e.g., role plays and scenarios) for outsource managers. In contrast, the AOTC used passive informal inductions comprising reading an annual report and operation manuals. The AFOGP outsource informants regarded their active induction sessions as effective, whereas the AOTC outsource informants considered their passive induction as ineffective. This is consistent with the need for induction to be an active rather than a passive process, in order to be effective (Seaver, 1997).

The AFOGP active induction sessions had the effect of developing team relationships amongst the event managers. The induction sessions drew managers together through discussions and role-plays, resulting in team management solutions. Therefore, active induction sessions signify team training (Blyton \& Turnbull, 1992; Henkoff, 1993; Wheatley, 1997), which leads to a strong commitment and more resilient organization (Wheately, 1997).

A consistent induction process for all managers had been overlooked at the AOTC and the AFOGP. Despite the number of years each event has been conducted, the development of a formalized and consistent induction process seems to be in its early stages. It could be assumed that the AOTC and the AFOGP are only now realizing the importance of induction in reducing personnel anxiety (Schermerhorn et al., 1993), increasing personnel retention (Cooke, 1997; Seaver, 1997), and improving productivity (Seaver, 1997). Perhaps for reason of inertial tendencies, whereby organizing the event itself consumes management time, induction has resulted in an inconsistent process and is not considered a priority. This supports Sligo (1995), who emphasized that when rapid organizational change occurs, personnel are less likely to have timely, reliable, and relevant information, and induction is not evident, resulting in managers retreating to the "grapevine" and making assumptions.

The number of informant recommendations on improving the induction process leads to the issue of evaluation. Results indicate that if evaluation was performed, and the induction process improved and formalized accordingly, there would be a significant increase in satisfaction amongst event managers. Consequently, implementing evaluation would assist in ensuring the satisfaction and partnerships of personnel (Elliott \& Torkko, 1996; Wheatley, 1997), and poor performance and manager's dissatisfaction would be reduced (Slack, 1997). Furthermore, seasonal informants, particularly from the AOTC, who felt deprived from suitable induction, would, according to Flynn (1996), feel a sense of belonging.

A formalized induction process for all full-time, outsource and seasonal managers did not exist at the AOTC or the AFOGP, even though there was clearly a need. This and other suggestions made by informants would have been resolved if the evaluation step was performed within each management category. Furthermore, if evaluated, managers would have felt their opinions were valued, resulting in personal responsibility and ownership of the event and their roles.

\section{A Formalized Induction Process at the AOTC and the AFOGP}

In light of the extant literature and from interpreting informant's responses, a detailed induction model has been proposed for managers at the AOTC and the AFOGP. Table 2 illustrates the four induction steps adapted from the "generic" organization induction process. Within these steps are induction strategies tailored for the two pulsating major sport event organizationsthat is, the inclusion of full-time, outsource and sea- 
Table 2

Proposed Induction Process for Managers at the AOTC and the AFOGP

\begin{tabular}{|c|c|c|c|c|}
\hline $\begin{array}{l}\text { Management } \\
\text { Category }\end{array}$ & Organizational Framework & Establishing Relationships & Providing Resources & Evaluating \\
\hline \multicolumn{5}{|l|}{ Full-time } \\
\hline New & Office-based session & Nurturing process & Information booklet & Review process \\
\hline Continuing & $\begin{array}{l}\text { Risk management session; } \\
\text { On-site session; On-site tour; } \\
\text { On-site safety session }\end{array}$ & $\begin{array}{l}\text { Induction briefing session; } \\
\text { Management brief; General event } \\
\text { session } \times 2 \text {; Social session }\end{array}$ & $\begin{array}{l}\text { Induction kit; Office } \\
\text { manual; Team manual; } \\
\text { On-site manual }\end{array}$ & $\begin{array}{l}\text { Review process; } \\
\text { Dress rehearsal }\end{array}$ \\
\hline \multicolumn{5}{|l|}{ Outsource } \\
\hline New & $\begin{array}{l}\text { Tender induction information; } \\
\text { Cultural event session }\end{array}$ & & $\begin{array}{l}\text { Tournament report; } \\
\text { Operations manual; } \\
\text { Detailed contract }\end{array}$ & Review process \\
\hline Continuing & $\begin{array}{l}\text { Emergency services session; } \\
\text { Risk management session; } \\
\text { On-site session; On-site tour; } \\
\text { On-site safety session }\end{array}$ & $\begin{array}{l}\text { Induction briefing session; } \\
\text { Management brief; } \\
\text { General event session } \times 2 \text {; } \\
\text { Social session }\end{array}$ & $\begin{array}{l}\text { Induction kit; On-site } \\
\text { manual; Team manual }\end{array}$ & $\begin{array}{l}\text { Review process; } \\
\text { Dress rehearsal }\end{array}$ \\
\hline \multicolumn{5}{|l|}{ Seasonal } \\
\hline New & $\begin{array}{l}\text { Office-based session; } \\
\text { Observer session }\end{array}$ & Working group meetings & $\begin{array}{l}\text { Induction checklist; } \\
\text { Induction booklet }\end{array}$ & Review process \\
\hline Continuing & $\begin{array}{l}\text { Risk management session; } \\
\text { On-site session; On-site tour; } \\
\text { On-site safety session; } \\
\text { Tournament information sent }\end{array}$ & $\begin{array}{l}\text { Management brief; } \\
\text { General event session } \times 2 \text {; } \\
\text { Social session }\end{array}$ & $\begin{array}{l}\text { Induction kit; } \\
\text { On-site manual; } \\
\text { Team manual }\end{array}$ & $\begin{array}{l}\text { Progressive meetings; } \\
\text { Review process; } \\
\text { Dress rehearsal }\end{array}$ \\
\hline
\end{tabular}

Note: New managers also involved with continuing manager's induction.

sonal managers, who all have different needs, attitudes, and expertise, and form temporary work units consisting of small cross-disciplinary teams. For example, tender induction information is tailored for outsource managers, and general event sessions are conducted for all management categories in order to ensure the formation of teams.

The nonitalicized information illustrates the extent of induction currently performed at the AOTC and the AFOGP. The italicized information indicates the additional proposed induction strategies for these pulsating major sport event organizations.

Within the organizational framework step, the italicized tender induction information to outsource managers would involve the event organization providing detailed requirements on how outsource managers were to induct their personnel (e.g., an information session on the major sport event, a detailed induction handbook for managers to refer to during the event, and onsite induction). This tender induction information would be provided when documents are initially sent to outsource applicants, to ensure they have a clear understanding of the time and duties required.
An additional strategy that aims to establish relationships with all managers is the social induction session. It is recommended that this session be held approximately 2 weeks prior to the event. During the session managers would provide a general overview of the event, display the organizational structure, which illustrates the importance of where all managers "fit" into the organization, and generally motivate managers (new and continuing) for the upcoming event.

To assist with providing resources to new seasonal managers, a checklist is recommended. This would be distributed to seasonal managers prior to their first day at work, so they could be aware that a formalized induction would be performed. Information such as the induction sessions and meeting respective managers and the department team could be included.

In addition to the checklist, an induction booklet has been recommended for seasonal managers. This is particularly important because many managers arrive during the busy time leading up to the event. The booklet would contain information such as descriptive role information, the reporting systems, and the department team. From the informant results, seasonal managers 
had many suggestions as to what content should be included when developing such a booklet. Therefore, one suggestion is to design this booklet with the assistance from managers who are currently in these roles. It is recommended that all resources be placed on the organization's intranet, to facilitate access by managers with computers. Upon appointment, managers could be provided with a computer access code to retrieve the organizations' induction information. This allows for immediate access and quick referral to answers before the event. Furthermore, it would complement the successful on-site manual, which was incorporated within both organizations.

One notable inclusion in Table 2 is evaluating the induction process. It is recommended that a review process for all managers be incorporated into this step. Examples include reviewing job descriptions or tenders, distributing questionnaires, and performing interviews and debriefing sessions. A team report would also be required, outlining information such as statistics and outcomes.

An additional evaluation strategy is to conduct an event prior to the major event, which is referred to as a dress rehearsal (see Table 2). This could be an evaluation process whereby the majority of managers are employed at this lead-up event, resulting in relationships being established, ensuring resources are effective, and addressing any issues occurring before the major event. The final recommended evaluation strategy is to conduct progressive meetings with seasonal managers over their contract time. This would provide an opportunity for questions to be answered and further promote the establishment of relationships.

Findings revealed the timing of the induction process is a critical issue. At the AOTC and the AFOGP, the timing varied among the management categories and the types of induction being performed. For example, the general event session was conducted one week before an event. From data interpretation, conducting induction as close to the event as feasible would ensure information retention by managers.

\section{Concluding Comments}

This article extends from the neglected research of induction at pulsating major sport event organizations, by describing the induction processes at the AOTC and the AFOGP, and by providing a model tailored for managers, within these two organizations. The model is in effect a typology, whereby it assists in identifying the strategies required for formalizing an induction process, for full-time, outsource and seasonal managers.

Considering that a formalized induction process within these two prominent organizations is at the "infant" stage, implications for future research are strong. Such a research endeavor could identify if other pulsating major sport event organizations have also adapted a "generic" organization induction process and consequently neglected incorporating their specialized characteristics, which are the fluctuation of varied personnel, all with different needs, attitudes, and expertise, who form temporary, small, cross-disciplinary teams for a limited period of time (Hanlon \& Jago, 2000). If this is the case, questions arise concerning why such an important manager's component has been neglected. In addition, having established a typology, this could be the first step for future research in determining the suitability of this model for other pulsating major sport event organizations. Furthermore, research could identify manager's job performance, commitment, satisfaction, and retention levels if a formalized induction process was evident within these organizations. In doing so, this would further enhance the understanding of managing managers in pulsating major sport event organizations.

This study has contributed to advancing knowledge, by identifying that adapting the four-step induction process from "generic" organizations and not considering the characteristics of pulsating major sport event organizations leads to inconsistent induction practices and dissatisfied managers. This study has identified the induction process of two pulsating major sport event organizations, highlighted the gaps associated with their induction process, and created an associated model to guide event managers in the future. This model could assist other pulsating major sport event organizations to develop, implement, and evaluate their induction process accordingly.

\section{References}

Australian Formula One Grand Prix. (1999). Australian Formula One Grand Prix scope of event staff operations booklet. Unpublished.

Babbie, E. (1998). The practice of social research (8th ed.). Belmont, CA: Wadsworth.

Barnard, B. (1990, May). The dynamics of events management case study - the Australian Motorcycle Grand Prix. Presented at Sports Management and Marketing Conference, Sydney, Australia. 
Blyton, P., \& Turnbull, P. (Eds.). (1992). Reassessing human resource management. London: Sage.

Brown, S., Sutton, W., \& Duff, G. (1993). The event pyramid: An effective management strategy. Sport Marketing Quarterly, 2(4), 29-35.

Brown, T. (1996). Giving it away. Successful Methods, 45(3), 107-109.

Cooke, R. (1997). Managing turnover. Credit Union Management, 20(7), 48-50.

Crawford, R. (1991). In the era of human capital: The emergence of talent, intelligence, and knowledge and the worldwide economic force and what it means to managers and investors. New York: HarperBusiness.

Critten, P. (1994). Human resource management in the leisure industry. Harlow, England: Longman.

Culkin, S. F., \& Kirsch, S. L. (1986). Managing human resources in recreation and leisure services. New York: Macmillan.

Cuskelly, G. (2000, June). An application of the theory of planned behaviour to predicting the dependability of volunteer staff at major sport events. Paper presented at the North American Society for Sport Management 15th Annual Conference, Colorado Springs, US.

Dale, M., \& Iles, P. (1996). Assessing management skills: A guide to competencies and evaluation techniques. London: Kogan Page.

Denzin, N. K., \& Lincoln, Y. S. (Eds.). (1994). Handbook of qualitative research. Newbury Park, CA: Sage.

Doherty, A. J. (1998). Managing our human resources: A review of organizational behaviour in sport. Sport Management Review, 1, 1-24.

Elliott, T. L., \& Torkko, D. E. (1996). World-class outsourcing strategies. Telecommunications, 30(8), 47-52.

Flynn, G. (1996). HR's game plan for the Olympics. Personnel Journal, 75(7), 72-76.

Getz, D. T. (1997). Event management and event tourism. New York: Cognizant Communication Corporation.

Go, F. M., Monachello, M. L., \& Baum, T. (1996). Human resource management in the hospitality industry. New York: John Wiley \& Sons.

Graham, S., Goldblatt, J. J., \& Delph, L. (1995). The ultimate guide to sport event management and marketing. Homewood, IL: Richard Irwin.

Green, B. C. (2001). Leveraging subculture and identity to promote sport events. Sport Management Review, 4(1), 1-19.

Hall, C. M. (1992). Hallmark tourism events: Impacts, management and planning. London: Belhaven Press.

Hanlon, C. (2001). Managing the pulsating effect at major sport event organizations. Manuscript in preparation, Victoria University, Victoria, Australia.

Hanlon, C., \& Jago, L. (2000). Pulsating sport events: An organizational structure to optimise performance. In J. Allen, R. Harris, L. Jago, \& A. Veal (Eds.), Proceedings of conference on event evaluation, research and education (pp. 93-105). Sydney, Australia: Australian Centre for Event Management.

Henkoff, R. (1993). Companies that train best. Fortune, 127(6), $42-49$

Jago, L., \& Shaw, R. (1998). Special events: A conceptual and definitional framework. Festival Management \& Event Tourism, 5(1/2), 21-32.

James, D. (1996). Genuine leadership is a growing problem. Business Review Weekly, 18(34), 64-66.

Katz, D., \& Kahn, R. (1978). The social psychology of organizations (2nd ed.). New York: Wiley.

Larsen, J. K., Montelpare, W., \& Donovan-Neale, W. (1992). The development of a municipal policy for volunteers in recreation and cultural services. Ontario, Canada: Ontario Research Council on Leisure.

Legge, K. (1995). Human resource management: Rhetorics and realities. Hampshire, London: Macmillan.

Minichiello, V., Aroni, R., Timewell, E., \& Alexander, L. (1995). In-depth interviewing: Principles, techniques, analysis (2nd ed.). Melbourne, Australia: Longman.

Mull, R. F., Bayless, K. G., Ross, C. M., \& Jamieson, L. M. (1997). Recreational sport management (3rd ed.). Champaign, IL: Human Kinetics.

Nankervis, A. R., Compton, R. L., \& McCarthy, T. E. (1996). Strategic human resource management (2nd ed.). South Melbourne, Australia: Thomas Nelson.

Parker, J. (1997, June). Generation X and the struggle for a career. HRMonthly, 20.

Pessin, F. (1997). In-house staff training programs. Fitness Management, 13(4), 35-38.

Peters, T. (1993). Liberation management: Necessary disorganization for the nanosecond nineties. New York: Knopf.

Schermerhorn, J. R., Jr., Naumes, W., \& Naumes, M. J. (Eds.). (1993). Management for productivity (4th ed.). Canada: Wiley $\&$ Sons.

Schraub, J. J., \& Katz, D. C. (1998, May). Putting teeth into management training. HRFocus, 13-14.

Seaver, J. B. (1997). An orientation process for new nurse managers. Nursing Management, 28(10), 53-55.

Slack, T. (1997). Understanding sport organizations: The application of organization theory. Champaign, IL: Human Kinetics.

Sligo, F. (1995). Information loss revisited: How different levels of staff perceive their access to work-related knowledge. Asia Pacific Journal of Human Resources, 33(1), 60-74.

Smith, A., \& Stewart, B. (1999). Sports management: A guide to professional practice. St Leonards, NSW: Allen \& Unwin.

Spilling, O. (1996). Mega-event as a strategy for regional development: The case of the 1994 Lillehammer Olympic Games. In Proceedings of Institute of Tourism and Service Economics, International Centre for Research and Education in Tourism, International Conference (pp. 128-154). Innsbruck.

Toffler, A. (1990). Future shock. New York: Bantam Books.

Torkildsen, G. (1992). Leisure and recreation management (3rd ed.). London, UK: Spon.

Vallance, I. (1994). From minor sport to major force. Personnel Management, 26(9), p. 24.

Victoria Racing Club. (1997). Annual report. Melbourne, Australia: Amanda Roach Design.

Wheatley, M. (1997, July/August). Evaluating the top administrator: A new approach. Nonprofit World, 14-17. 